\title{
Segmental neurofibromatosis
}

\author{
Michał Sobjanek $^{1}$, Magdalena Dobosz-Kawałko ${ }^{1,2}$, Igor Michajłowski ${ }^{1}$, Rafał Pęksa ${ }^{3}$, Roman Nowicki ${ }^{1}$
}

${ }^{1}$ Department of Dermatology, Venereology and Allergology, Medical University of Gdansk, Gdansk, Poland

Head of the Department: Prof. Roman Nowicki MD, PhD

${ }^{2}$ Department of Plastic Surgery, Medical University of Gdansk, Gdansk, Poland

Head of the Department: Alicja Renkielska MD, PhD

${ }^{3}$ Department of the Pathomorphology, Medical University of Gdansk, Gdansk, Poland

Head of the Department: Prof. Wojciech Biernat MD, PhD

Postep Derm Alergol 2014; XXXI, 6: 410-412

DOI: $10.5114 /$ pdia.2014.40942

\begin{abstract}
Segmental neurofibromatosis or type $V$ neurofibromatosis is a rare genodermatosis characterized by neurofibromas, café-au-lait spots and neurofibromas limited to a circumscribed body region. The disease may be associated with systemic involvement and malignancies. The disorder has not been reported yet in the Polish medical literature. A 63-year-old Caucasian woman presented with a 20-year history of multiple, flesh colored, dome-shaped, soft to firm nodules situated in the right lumbar region. A histopathologic evaluation of three excised tumors revealed neurofibromas. No neurological and ophthalmologic symptoms of neurofibromatosis were diagnosed.
\end{abstract}

Key words: segmental neurofibromatosis, type $V$ neurofibromatosis, mosaic-localized neurofibromatosis type 1.

\section{Introduction}

Neurofibromatosis (NF) is a relatively frequent genodermatosis presenting with heterogeneous clinical features. The NF is characterized by the presence of neurofibromas, café-au-lait macules and freckles as well as some neurologic and ophthalmologic symptoms. Segmental neurofibromatosis (SN) known also as a type $\mathrm{V}$ neurofibromatosis or mosaic-localized neurofibromatosis is a rare variant of the disease characterized by cutaneous lesions limited to a circumscribed body segment.

Despite the fact that NF is one of the most common inherited diseases (incidence $1 / 3000$ births), SN is very rare with an incidence 10 to 20 times lower than NF. In the worldwide medical literature, approximately 100 cases of SN have been described so far. We present the first Polish patient with SN [1-3].

\section{Case report}

A 63-year-old Caucasian woman presented with a 20year history of multiple, flesh colored, dome-shaped, soft to firm nodules situated in the right lumbar region. Several tumors were painful (Figure 1). Café-au-lait spots, axillary freckling and Lisch nodules were not observed. There was no family history of NF. The patient also suffered from cataract and dizziness. Craniospinal magnetic resonance and computer tomography revealed no abnormalities.
A histopathologic examination of the three excised tumors revealed small spindled cells with "s-shaped" nuclei, vessels and small nerve fibers (Figure 2).

According to clinical and histopathologic features, the diagnosis of SN was established.

\section{Discussion}

First patients with symptoms of SN were described by Gammel [4] in 1931 and Crowe et al. [5] in 1956. The term "segmental neurofibromatosis" was introduced by Miller and Sparkes [6] in 1977. Because of the variability of clinical manifestations of NF, Riccardi [7] in 1982 classified NF into eight categories. Type $\vee$ was reserved for SN. In 1987, Roth et al. [8] subdivided NF into four variants: true segmental, localized with deep involvement, hereditary and bilateral. Our patient presents true segmental SN.

Aethiopathogenesis of NF is associated with postzygotic mutation in the NF1 gene leading to somatic mosaicism. In SN, mutation occurs late during the embryonic development what provokes localized disease [9]. This concept of mosaicism explains the variety of clinical presentations of segmental NF, which may be predicted by the timing of the NF1 mutation, the particular lineage and the viability of the cells bearing the mutation. Most patients did not have a family history of NF so SN is considered as a non-inherited disorder [2, 9].

Address for correspondence: Michat Sobjanek MD, PhD, Department of Dermatology, Venereology and Allergology, Medical University of Gdansk, 7 Debinki St, 80-211 Gdansk, Poland, phone: +48 5834925 80, fax: +48 58349 25 83, e-mail: sobjanek@wp.pl Received: 1.10.2013, accepted: 29.10.2013. 


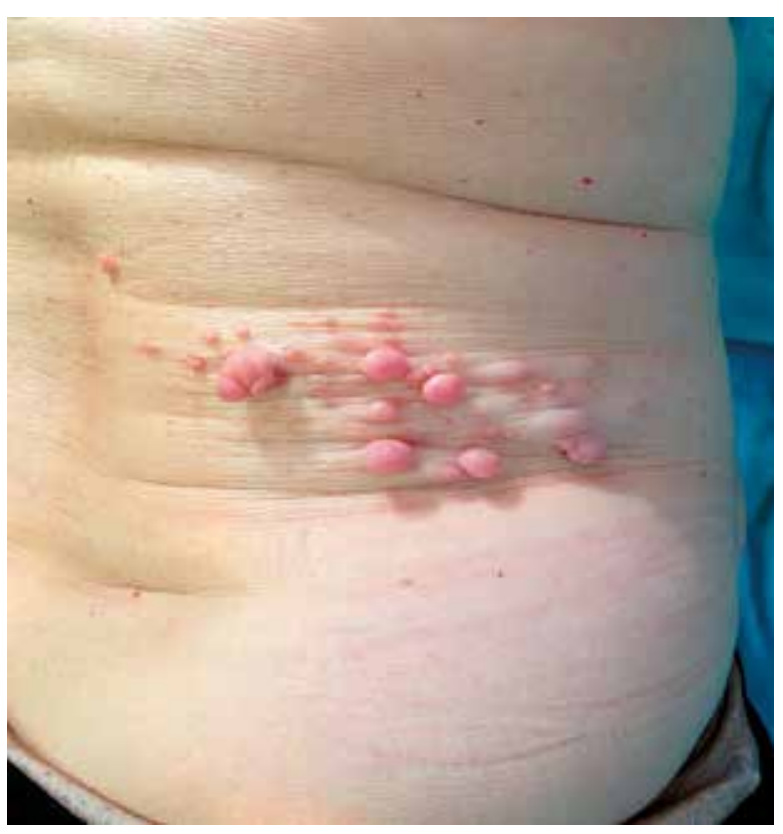

Figure 1. Segmental neurofibromatosis: clinical features. Multiple, flesh colored, dome-shaped, soft to firm nodules situated in the right lumbar region

Prevalence of SN is estimated between 0.0014$0.002 \%$. Ingordo et al. [10] analyzed a group of 56,183 young men between the age of 17 and 80 . In this group, 11 cases of NF, with a relative frequency of $0.020 \%$, have been found. However, during the same period, only one case of SN has been observed (relative frequency $0.0018 \%$ ). Basing on these observations, the authors concluded that SNFs are probably not underdiagnosed but are 10 times more infrequent than other forms of NF. The disease occurs twice more often in females. There is a bimodal peak of onset at 10 to 30 years and 50 to 70 years [1-3].

The most common manifestation of SN is neurofibromas, and less frequently, café-au-lait spots and axillary freckling. Clinically, patients may be divided into four groups: with only pigmentary lesions, with only neurofibromas, with both pigmentary lesions and neurofibromas, and with isolated plexiform neurofibromas. In most cases, lesions follow the lines of Blaschko. Lesions are usually unilateral (approximately $6 \%$ of cases are bilateral) and occupy single dermatome [1, 2, 11, 12].

In contrast to NF I and NF II, systemic involvement in SN seems to be uncommon, except patients with plexiform neurofibromatomas [1, 2, 13, 14].

Patients with NF I are at an increased risk of certain malignancies. That phenomenon is also observed in SN patients. Malignancies associated with SN include peripheral nerve sheath tumor, malignant melanoma, breast cancer, colon cancer, gastric cancer, lung cancer, and Hodgkin lymphoma. The most common ones are de-

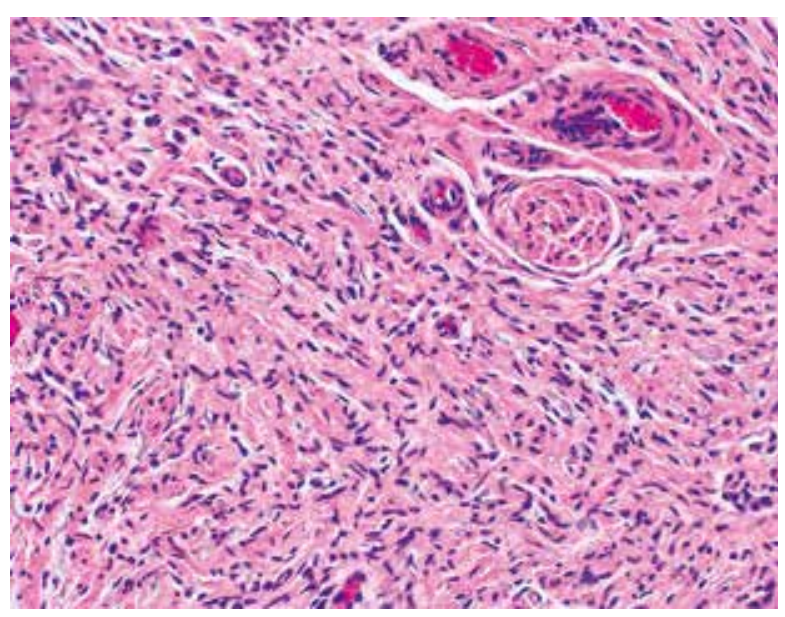

Figure 2. Neurofibroma: histopathologic features. Typical small spindled cells with "s-shaped" nuclei, vessels and small nerve fibers are visible

rived from neural crest cells: malignant peripheral nerve sheath tumor and malignant melanoma [15].

\section{Conclusions}

We present the first Polish case of SN with typical clinical features. The true risk of systemic involvement and internal malignancies is not established, therefore patients with SN should undergo a long-term, multi-disciplinary follow-up.

\section{References}

1. Hager CM, Cohen PR, Tschen JA. Segmental neurofibromatosis: case reports and review. Am J Acad Dermatol 1997; 37: 864-9.

2. Morais P, Ferreira O, Bettencourt H, Azevedo F. Segmental neurofibromatosis: a rare variant of a common genodermatosis. Acta Dermatovenerol Alp Panonica Adriat 2010; 19: 27-9.

3. Ruggieri M, Huson SM. The clinical and diagnostic implications of mosaicism in the neurofibromatoses. Neurology 2001; 56: 1433-43.

4. Gammel JA. Localized neurofibromatosis. Arch Dermatol Syph 1931; 24: 712-5.

5. Crowe FW, Schull WJ, Neel JV. Clinical, pathological, and genetic study of multiple neurofibromatosis. Springfield (IL): Charles C Thomas 1956; 181.

6. Miller RM, Sparkes RS. Segmental neurofibromatosis. Arch Dermatol 1977; 123: 837-8.

7. Riccardi VM. Neurofibromatosis: clinical heterogeneity. Curr Probl Cancer 1982; 7: 1-34.

8. Roth RR, Martines R, James WD. Segmental neurofibromatosis. Arch Dermatol 1987; 123: 917-20.

9. Tinschert S, Naumann I, Stegmann E, et al. Segmental neurofibromatosis is caused by somatic mutation of the neurofibromatosis type 1 (NF1) gene. Eur J Hum Genet 2000; 8: 455-9. 
10. Ingordo V, D’Andria G, Mendicini S, et al. Segmental neurofibromatosis: is it uncommon or underdiagnosed? Arch Dermatol 1995; 131: 959-60.

11. Gabhane SK, Kotwal MN, Bobhate SK. Segmental neurofibromatosis: a report of 3 cases. Indian I Dermatol 2010; 55: 105-8.

12. Gonzalez G, Russi ME, Lodeiros A. Bilateral segmental neurofibromatosis: a case report and review. Pediatr Neurol 2007; 36: 51-3.

13. Niiyama S, Satoh K, Kaneko S, et al. Segmental neurofibromatosis. Acta Derm Venereol 2005; 85: 448-9.

14. Tanito K, Ota A, Kamide R, et al. Clinical features of 58 Japanese patients with mosaic neurofibromatosis 1. J Dermatol 2014; 41: 724-8.

15. Dang JD, Cohen PR. Segmental neurofibromatosis and malignancy. Skinmed 2010; 8: 156-9. 